\title{
EVALUASI PERFORMA WEBSITE BERDASARKAN PENGUJIAN BEBAN DAN STRESS MENGGUNAKAN LOADIMPACT (STUDI KASUS WEBSITE IAIN SALATIGA)
}

\author{
Agung Suprapto ${ }^{1}$, Dimas Sasongko ${ }^{2 *}$ \\ 1) Program Studi Komunikasi Penyiaran Islam, Fakultas Dakwah, IAIN Salatiga \\ Jl. Lingkar Salatiga, PO. BOX 323433, Sidorejo, Salatiga \\ ${ }^{2 *}$ Program Studi TeknikInformatika, Fakultas Teknik, Universitas Muhammadiyah Magelang \\ Jl Mayjend Bambang Soegeng, PO. BOX 56172, Mertoyudan, Magelang \\ Email: suprapto.agung@iainsalatiga.ac.id ${ }^{l}$, dimassasongko@ummgl.ac.id ${ }^{2 *}$
} Corresponding author. Phone : +62 82142442077

\begin{abstract}
Abstrak
Penelitian inimenyajikan hasilpengujian beban dan stress pada website IAIN Salatiga meng gunakan tools Loadimpact. Penelitian dilakukan dengan empat tahap utama yaitu: observasitraffic website, perancangan skenario pengujian beban website, pengujian beban website, dan analisis data hasil pengujian beban website. Berdasarkan hasil pengujian yang sudah dilakukan pada website IAIN Salatiga hasilnya adalah (i) tidak ditemukan adanya kegagalan HTTP pada website IAIN Salatiga, (ii) konsumsi CPU tertinggi berada pada tingkat yang sangat baik yaitu sekitar $6-11 \%$, dan (iii) konsumsi memory berada pada tingkat yang sangat baik yaitu sekitar $2-4 \%$. Walaupun terdapattemuan permasalahan bottlenecksaat pengujian dengan jumlah virtual user 50 dan durasi pengujian 5 menit, namun secara keseluruhan tidak menjadi permasalahan serius pada website IAIN Salatiga. Penelitian yang dilakukan masih memiliki keterbatasan yaitu aplikasi yang digunakan pada penelitian ini masih menggunakan versi free, sehingga masih memiliki keterbatasan pada penggunaan jumlah virtual user, durasi waktu pengujian, dan lokasi pengujian. Hasil penelitian ini dapat digunakan oleh akademis dan praktisi pada bidang kajian evaluasi website dan temuan dari penelitian inidapat menjadiperhatian bagipengembang website dalam membangun sebuah website.
\end{abstract}

Kata kunci: Pengujian Website, Performa Website, Pengujian Beban Website, Pengujian Stress Website

\begin{abstract}
This study demonstrates the findings of load and stress test on the IAIN Salatiga's website through using Loadimpact tools. The study has been carried out into four phases, they are: website traffic observation, website load test scenario design, then followed by website load test and data analysis. The findings of the study on IAIN Salatiga's website show that (i) there is no HTTP's failure on the IAIN Salatiga website, (ii) the highest CPU's consumption exists at a very good level approximately $6-11 \%$, and (iii) the memory consumption shows a very good level approximately $2-4 \%$. Despite there is a bottleneck issue which has been found during the test of 50 virtual users and 5 minutes of testing duration, this is not such a serious challenge for the IAIN Salatiga's website. In addition, the study still has the limitation on the application due to the use offree version that influenced the limitations on the virtual users'number, testing duration and test site. The findings of this study can be used by academics and practitioners in the field of website evaluation studies and for the further study that concerning on building website by website developers.

Keywords : Website Test, Website Performance, Website LoadTest, Website Stress Test
\end{abstract}

\section{PENDAHULUAN}

Teknologi Informasi (TI) telah mengalami perkembangan yang signifikan khususnya pada era industri 4.0. Dalam dunia bisnis, perkembangan TI dalam bentuk teknologi Internet dimanfaatkan untuk menyediakan sistem bisnis yang lebih baik khususnya dalam menyampaikan informasi kepada masyarakat [1], [2]. Teknologi Internet membuat organisasi di seluruh dunia terus mengembangkan solusi berbasis TI untuk meningkatkan kemudahan dan kualitas komunikasi [3]. Website merupakan salah satu produk perkembangan teknologi Internet yang dapat memberikan kemudahan dalam menyampaikan informasi. Transformasi penyampaian informasi dari model konvensional menjadi layanan digital yang cepat, fleksibel, efektif dan efisien, seperti menjadi tuntutan [4]. 
Masalah yang sering dihadapi oleh website adalah kecepatan akses halaman website [5]. Kecepatan akses halaman website menjadi sangat krusial untuk membuat pengguna Kembali mengunjungi halaman website tersebut. Website yang baik harus dapat diakses dengan mudah dan waktu menampilkan halaman yang cepat agar pengguna dapat dengan segera mendapatkan informasi yang dibutuhkan. Jika website yang diakses lambat, maka pengguna memerlukan waktu tunggu lama dan membuat pengguna merasa tidak nyaman ketikan mengakses website [6].

Institut Agama Islam Negeri (IAIN) Salatiga sudah memiliki website yang dapat diakses pada URL https://iainsalatiga.ac.id yang menampilkan informasi profil kampus dan update berita seputar kampus sebagai salah satu media untuk publikasi informasi. Agar pelayanan penyampaian informasi yang terdapat pada website IAIN Salatiga dapat terselenggara dengan baik, maka dibutuhkan pengujian terhadap performa. Pengujian performa dapat dilihat dari waktu load halaman website tersebut. Kecepatan loading suatu website akan meningkatkan pengalaman pengguna dan kenyamanan pengguna dalam memperoleh informasi [7].

Website harus dapat selalu dapat diakses oleh pengguna kapanpun dalam berbagai kondisi, sehingga diperlukan adanya pengujian performa terhadap kualitas website. Salah satu pengujian performa website adalah dengan melakukan pengujian beban tingkat stress pada sebuah website ketika diakses oleh pengguna [8].

Tujuan dari penelitian ini adalah melakukan pengujian beban dan stress website IAIN Salatiga. Pengujian dilakukan dengan tools Loadimpact (k6.io) [9] dan tools SimilarWeb untuk observasi traffic pengunjung website IAIN Salatiga. Pengujian akan dilaksanakan pada skenario yang berbeda-beda yaitu dimulai dari kondisi jaringan paling minimal sampai dengan kondisi jaringan paling ekstrem dan dengan kondisi jumlah virtual user yang bervariasi.

\section{DASAR TEORI}

\subsection{Penelitian Terkait}

Penelitian tentang pengujian beban tingkat stress website sudah dilakukan oleh peneliti sebelumnya. Reza Maulana melakukan pengujian performa website menggunakan tools GTMetrix dan pengujian beban website menggunakan tools Loadstorm [10]. Pada penelitian yang lain I Made Edy Listartha [11] dan Maria Christiana [12] melakukan pengujian performa website menggunakan GTMetrix dan WebPage Test sementara itu pengujian beban website menggunakan Loadimpact (k6.io). Pada penelitian sebelumnya yang sudah dilakukan tersebut tidak dijelaskan secara detail tentang pengujian beban yang sudah dilakukan, hasil pengujian lebih kepada hasil pengujian performa secara umum. Selain itu tidak dilakukan pengujian beban lebih terperinci dengan kondisi yang berbeda-beda, misalkan dalam jumlah virtual user yang berbeda.

\subsection{Pengujian Performa Website}

Performa dalam membuka sebuah website menjadi salah satu faktor yang akan membuat pengguna nyaman dalam menggunaan layanan. Performa ini akan dipengaruhi oleh ukuran file dari sebuah halaman yang dituju. Searah dengan fungsinya, semakin kompleks fungsi didalamnya akan membuat ukurannya menjadi semakin besar [13]. Faktor yang terkait dengan performa website adalah waktu yang dibutuhkan untuk menampilkan halaman website [14].

\subsection{Pengujian Beban/ Load Testing}

Load Testing merupakan bentuk sederhana dari pengujian performa dalam bentuk sebuah uji beban yang dilakukan untuk memahami perilaku sistem di bawah beban yang diharapkan secara spesifik. Pengujian akan dilakukan dengan memberikan sebuah respon dan data dari semua transaksi yang dilakukan sesuai skenario, sehingga dapat dengan mudah mencari kemacetan atau bottlenecks yang mempengaruhi performansi dari suatu sistem yang telah diuji [15].

Pengujian beban digunakan untuk menguji stabilitas dan keandalan sistem. Tes ini dapat menentukan sistem pada ketahanan dan penanganan kesalahan dalam kondisi beban yang sangat berat. Jumlah pengguna dalam suatu waktu dapat berubah-ubah dan dari pengujian beban akan melakukan pengujian tentang respon yang di berikan oleh website saat diakses dengan jumlah user tertentu dan dalam kurun waktu tertentu. Pada penelitian ini mengunakan aplikasi Loadimpact (app.k6.io), tampilan konfigurasi pengujian beban seperti yang terlihat pada Gambar 1. Aplikasi tersebut dipilih karena memiliki empat skenario pengujian beban, yaitu: load test 
adalah berkaitan dengan menilai kinerja sistem dalam hal pengguna bersamaan atau permintaan per detik., soak test adalah memberi tahu tentang keandalan dan kinerja sistem Anda selama periode waktu yang lama., spike test dan stress test adalah berkaitan dengan menilai batas sistem dan stabilitas dalam kondisi ekstrim. [16].

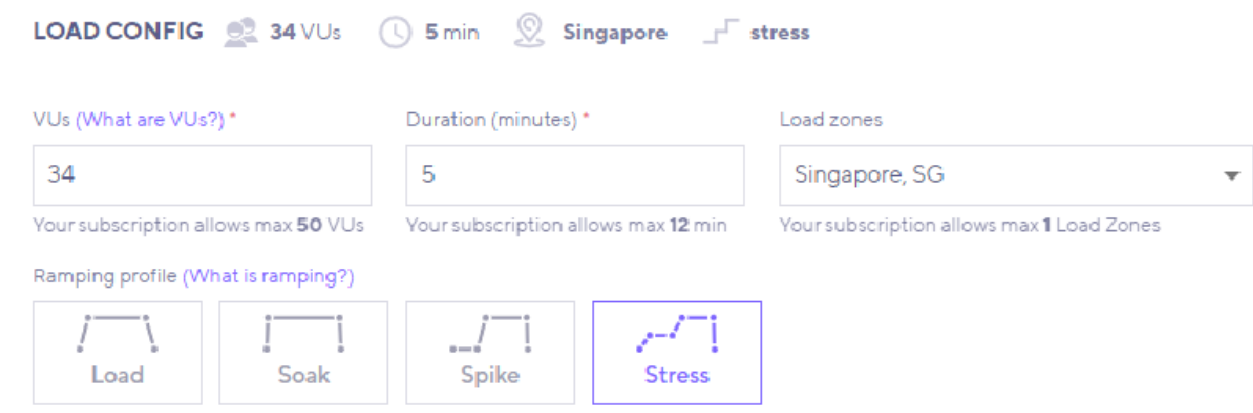

Gambar 1. Tampilan Konfigurasi Pengujian Pada Aplikasi Loadimpact (app.k6.io)

\section{METODOLOGI PENELITIAN}

Pada tahapan penelitian yang dilakukan seperti yang terlihat pada Gambar 2 terdiri dari alur penelitian, kegiatan penelitian, dan hasil keluaran. Penelitian dilakukan dengan empat tahap utama yaitu: observasi traffic website, perancangan skenario pengujian beban website, pengujian beban website, dan analisis data hasil pengujian beban website. Pengujian performa dilakukan dengan kondisi pengujian sebagai berikut: (i) Kecepatan internet downstream $17 \mathrm{Mbps}$ dan upstream $3 \mathrm{Mbps}$, pengukuran kecepatan koneksi dilakukan dengan menggunakan aplikasi pihak ketiga yaitu, speedtest.net., (ii) Waktu pengujian jam 09.00-16.00 GMT+7 pada hari kerja Senin sampai Jum'at, (iii) Perangkat keras Processor Intel Celeron $1.50 \mathrm{GHz}$ Memori $4 \mathrm{~GB}$, (iv) Perangkat lunak Sistem Operasi Windows 1064 bit, Google Chrome Version 7364 bit, dan (v) Aplikasi website Similarweb dan Loadimpact (app.k6.io).

Tabel 1. Perancangan Pengujian Beban

\begin{tabular}{|c|c|c|c|c|}
\hline No & Virtual User & Durasi (menit) & Lokasi & Skenario Pengujian \\
\hline 1 & 17 & 5 & Singapore & Load, Soak, Spike, Stress \\
\hline 2 & 34 & 5 & Singapore & Load, Soak, Spike, Stress \\
\hline 3 & 50 & 5 & Singapore & Load, Soak, Spike, Stress \\
\hline
\end{tabular}

Tahapan awal dari penelitian yang dilakukan adalah studi literatur. Studi literatur merupakan kegiatan penelitian terdiri dari kajian penelitian sejenis yang sudah dilakukan oleh peneliti sebelumnya dan kajian teori yang terkait dengan website dan pengujian beban website. Penelitian sejenis terkait pengujian beban website yang sudah dilakukan oleh peneliti sebelumnya dilakukan untuk mendapatkan keaslian penelitian dan menentukan kontribusi penelitian, pembahasan tentang penelitian yang dilakukan oleh penelitian sebelumnya dapat ditemukan pada tinjauan pustaka.

Observasi traffic website dilakukan menggunakan aplikasi berbasis web Similarweb. Similarweb mmeiliki fasilitas untuk melacak traffic website dari informasi jumlah pengunjung, jenis perangkat yang digunakan untuk mengunjungi website, bounce rate, dan geografis pengunjung website. Observasi traffic website memiliki tujuan untuk mendapatkan informasi tentang gambaran data dari pengunjung website IAIN Salatiga, khususnya jumlah pengunjung dan durasi kunjungan pada website tersebut. Data yang diperoleh pada Observasi traffic website akan digunakan sebagai dasar dalam membuat perancangan pengujian beban website.

Pengujian beban website akan menggunakan aplikasi web Loadimpact (app.k6.io). Penggunaan aplikasi Loadimpact dalam bentuk free memiliki keterbatasan yaitu jumlah maksimal virtual user (VU) adalah 50 dan durasi waktu pengujian maksimal 5 menit, hal tersebut juga menjadi keterbatasan dalam penelitian yang dilakukan. Pada penelitian yang dilakukan akan menggunakan skenario pengujian seperti yang terlihat pada Tabel 1, sesuai dengan skenario 
pengujian Ramping Virtual User yaitu sejumlah variabel Virtual User mengeksekusi pada jangka waktu tertentu [17]. Tahapan akhir dari penelitian adalah analisis hasil temuan pengujian beban untuk mendapatkan informasi yang dapat digunakan untuk mengembangkan website IAIN Salatiga.

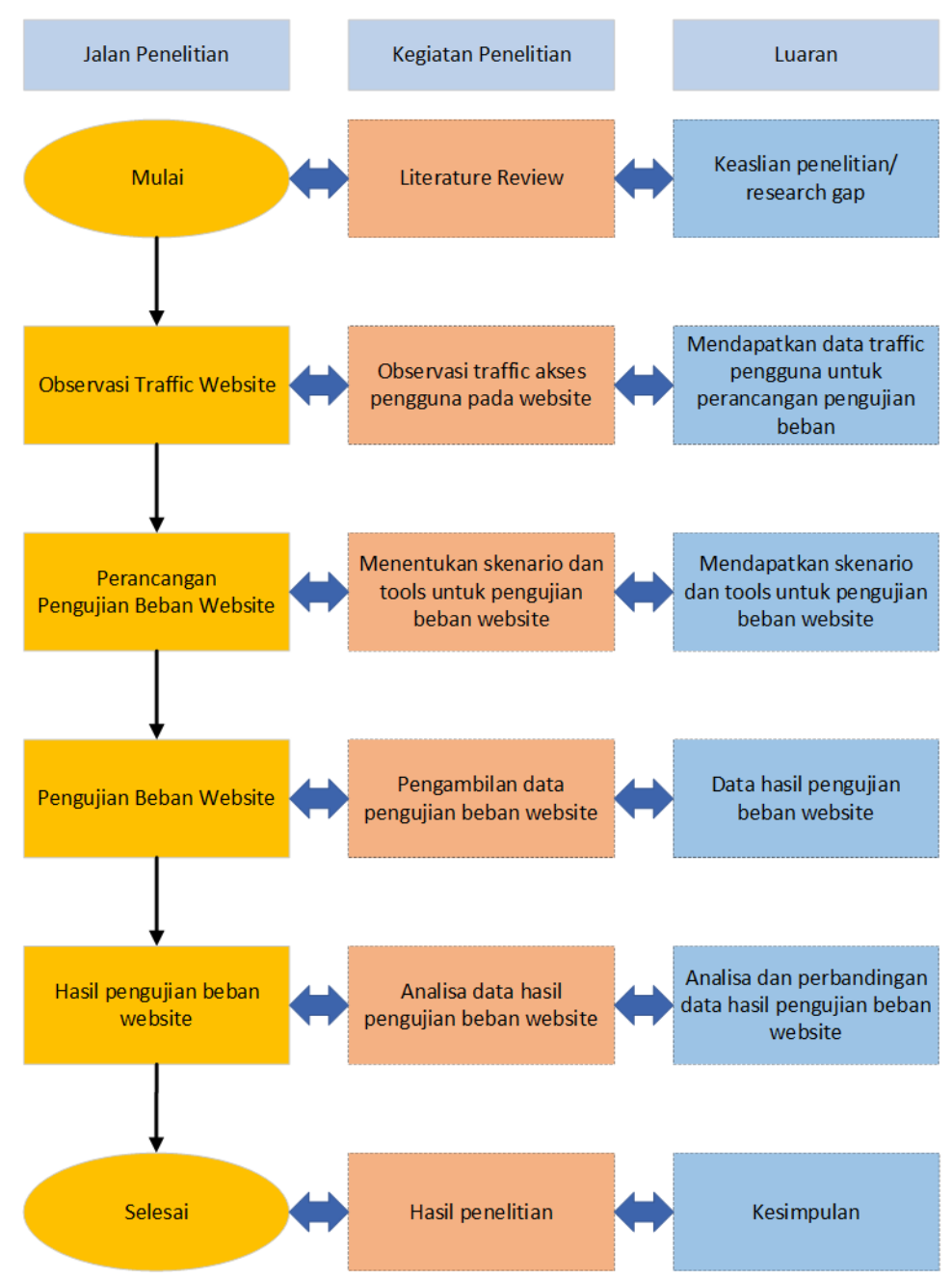

Gambar 2. Jalan Penelitian

\section{PENGUJIAN DAN PEMBAHASAN}

Engagement overview 1

酋 Oct 2020 - Dec 2020 5日 All Traffic (3) Worldwide

\begin{tabular}{|c|c|c|c|c|}
\hline 首 & Monthly visits $\odot$ & 495,367 & (ㄴ) Visit Duration (i) & 00:04:00 \\
\hline 요 & Monthly Unique Visitors $(i)$ & UPGRADE & 回 Pages / Visit (i) & 4.45 \\
\hline @̊ำ & Deduplicated audience (i) & UPGRADE & 侊 Bounce Rate (i) & $53.98 \%$ \\
\hline
\end{tabular}

Gambar 3. Hasil Observasi Traffic Website

Pengujian penelitian diawali dengan observasi traffic website. Observasi traffic website IAIN Salatiga menggunakan aplikasi Similarweb, hasil observasi jumlah pengunjung dan durasi kunjungan website dalam kurun waktu 3 bulan terakhir seperti yang terlihat pada Gambar 3. Selain itu berdasarkan hasil pengujian traffic website pengunjung website IAIN Salatiga didominasi oleh pengunjung dari negara Indonesia dan berdasarkan perangkat akses, website diakses oleh pengunjung menggunakan perangkat mobile. Bounce Rate website IAIN Salatiga 
berada diantara angka rata-rata $45 \%$ - 65\% yang dapat dikatakan sudah baik untuk ukuran website institusi [18].

Tahap berikutnya setelah melaksanakan observasi traffic website adalah melakukan pengujian beban menggunakan aplikasi berbasis web Loadimpact (app.k6.io), tampilan metrik dari hasil pengujian beban seperti yang terlihat pada Gambar 4. Informasi yang ditampilkan dalam hasil pengujian terdiri dari jumlah permintaan yang dibuat, kegagalan HTTP, rata-rata waktu tunggu, utilisasi CPU, dan utilisasi memory.

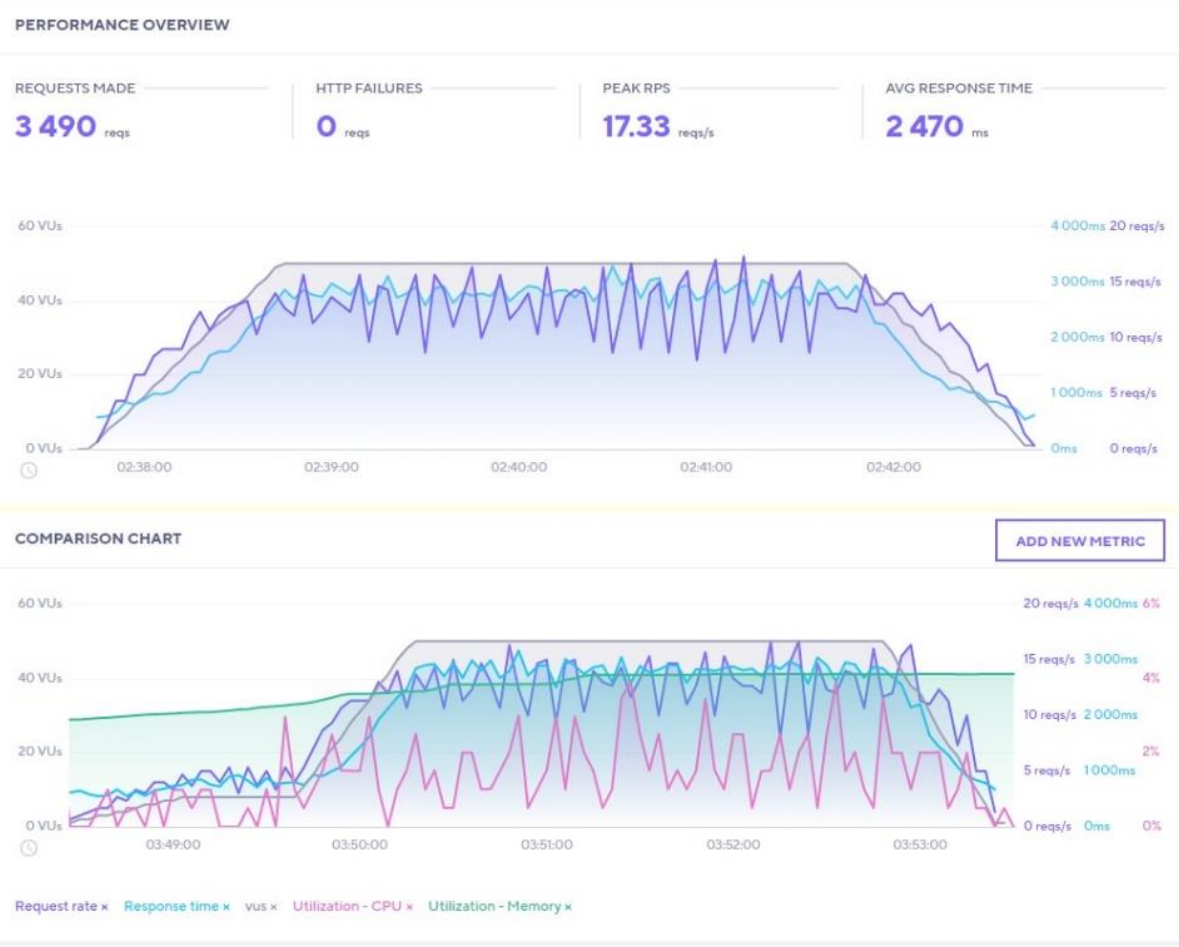

Gambar 4. Tampilan Metrik Pengujian Beban

Pengujian dilakukan sesuai dengan perancangan skenario pengujian beban yang terdapat pada Tabel 1. Rekapitulasi hasil pengujian beban kepada website IAIN Salatiga yang sudah dilaksanakan seperti yang terdapat pada Tabel 2. Berdasarkan pengujian beban website IAIN Salatiga memiliki performa sangat baik, hal tersebut dibuktikan dengan: (i) tidak ditemukan adanya kegagalan HTTP pada website IAIN Salatiga, (ii) konsumsi CPU tertinggi berada pada tingkat yang sangat baik yaitu sekitar $6-11 \%$, dan (iii) konsumsi memory berada pada tingkat yang sangat baik yaitu sekitar $2-4 \%$.

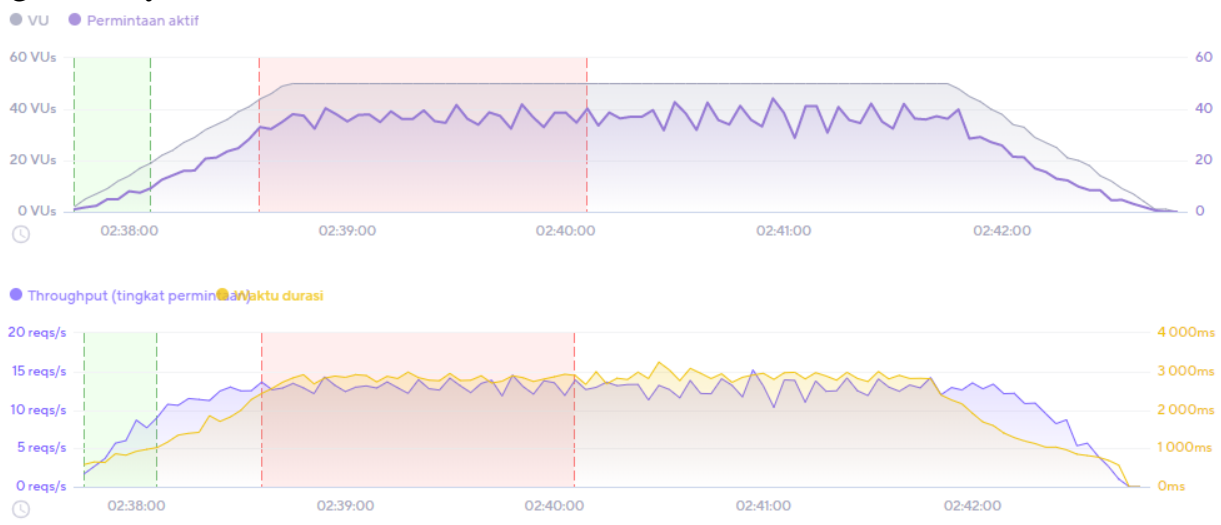

Gambar 5. Tampilan Metrik Masalah Kinerja

Terdapat permasalahan dideteksi oleh aplikasi pengujian, namun hanya berada pada skenario pengujian beban Load, Spike, dan Stress dengan 50 virtual users dan durasi pengujian 5 menit. Permasalahan yang dihadapi adalah sama yaitu pada waktu tertentu sistem mengalami bottleneck seperti yang terlihat pada Gambar 5. Jumlah permintaan aktif terus bertambah seiring 
dengan bertambahnya jumlah VU, sementara Throughtput (permintaan selesai) tidak berubah yang menunjukkan bahwa sistem yang diuji kelebihan beban dan menghasilkan waktu respon yang lebih tinggi.

Tabel 2. Pengujian Beban

\begin{tabular}{|c|c|c|c|c|c|c|c|c|}
\hline No & $\begin{array}{l}\text { Virtual } \\
\text { User }\end{array}$ & Skenario & Request & Failure & $\begin{array}{c}\text { Average } \\
\text { Response } \\
\text { Time (ms) }\end{array}$ & $\begin{array}{c}\text { Peak } \\
\text { Request } \\
\text { Per Second }\end{array}$ & $\begin{array}{l}\text { Peak } \\
\text { CPU }\end{array}$ & $\begin{array}{c}\text { Peak } \\
\text { Memory }\end{array}$ \\
\hline \multirow{5}{*}{1} & \multirow{4}{*}{17} & Load & 2104 & 0 & $962 \mathrm{~ms}$ & 10.67 & $6.05 \%$ & $2.49 \%$ \\
\hline & & Soak & 2324 & 0 & $989 \mathrm{~ms}$ & 10.67 & $8.03 \%$ & $2.48 \%$ \\
\hline & & Spike & 1747 & 0 & $923 \mathrm{~ms}$ & 11.33 & $5.97 \%$ & $2.57 \%$ \\
\hline & & Stress & 1610 & 0 & $875 \mathrm{~ms}$ & 11.33 & $6.03 \%$ & $2.47 \%$ \\
\hline & \multicolumn{2}{|c|}{ Rata-rata } & 1946.25 & 0 & $937.25 \mathrm{~ms}$ & 11.00 & $6.52 \%$ & $2.50 \%$ \\
\hline \multirow{5}{*}{2} & \multirow{4}{*}{34} & Load & 3785 & 0 & $1177 \mathrm{~ms}$ & 18.67 & $11.82 \%$ & $3.37 \%$ \\
\hline & & Soak & 4298 & 0 & $1149 \mathrm{~ms}$ & 18.33 & $10.05 \%$ & $3.49 \%$ \\
\hline & & Spike & 3221 & 0 & $1108 \mathrm{~ms}$ & 17.67 & $11.00 \%$ & $3.41 \%$ \\
\hline & & Stress & 3013 & 0 & $1044 \mathrm{~ms}$ & 17.67 & $12.32 \%$ & $3.03 \%$ \\
\hline & \multicolumn{2}{|c|}{ Rata-rata } & 3579.25 & $\mathbf{0}$ & $1119.5 \mathrm{~ms}$ & 18.08 & $11.30 \%$ & $3.33 \%$ \\
\hline \multirow{5}{*}{3} & \multirow{4}{*}{50} & Load & 3490 & 0 & $2470 \mathrm{~ms}$ & 17.33 & $14.36 \%$ & $4.23 \%$ \\
\hline & & Soak & 3683 & 0 & $2693 \mathrm{~ms}$ & 17.33 & $14.85 \%$ & $4.03 \%$ \\
\hline & & Spike & 2980 & 0 & $2376 \mathrm{~ms}$ & 16.67 & $3.92 \%$ & $4.12 \%$ \\
\hline & & Stress & 3155 & 0 & $1874 \mathrm{~ms}$ & 16.67 & $13.86 \%$ & $4.26 \%$ \\
\hline & \multicolumn{2}{|c|}{ Rata-rata } & 3327 & $\overline{0}$ & $2353.25 \mathrm{~ms}$ & 17 & $11.54 \%$ & $4.16 \%$ \\
\hline
\end{tabular}

\section{KESIMPULAN}

Berdasarkan hasil observasi dan pengujian yang sudah dilakukan hasilnya adalah website IAIN Salatiga memiliki Bounce Rate berada diantara angka rata-rata 45\% - 65\% yang dapat dikatakan sudah baik untuk ukuran website institusi. Berdasarkan pengujian beban website IAIN Salatiga memiliki performa sangat baik, hal tersebut dibuktikan dengan: (i) tidak ditemukan adanya kegagalan HTTP pada website IAIN Salatiga, (ii) konsumsi CPU tertinggi berada pada tingkat yang sangat baik yaitu sekitar 6 - 11\%, dan (iii) konsumsi memory berada pada tingkat yang sangat baik yaitu sekitar $2-4 \%$. Penelitian yang dilakukan masih memiliki keterbatasan yaitu penggunaan aplikasi pengujian beban masih menggunakan versi free sehingga masih memiliki keterbatasan pada penggunaan jumlah virtual user, durasi waktu pengujian, dan lokasi pengujian. Developer atau pengembang website dapat menggunakan aplikasi Loadimpact (app.k6.io) untuk melakukan pengujian beban, seperti yang sudah dilakukan pada penelitian ini yaitu melakukan pengujian beban pada website IAIN Salatiga. Salah satu keunggulan dari menggunakan aplikasi Loadimpact (app.k6.io) adalah dapat menggunakan 4 macam skenario pengujian beban load test, soak test, spike test, dan stress test, selain itu juga dapat disesuaikan dengan menggunakan konfigurasi jumlah virtual user, durasi waktu pengujian, dan lokasi pengujian.

\section{Daftar Pustaka}

[1] Y. S. Putra, M. T. Indriastuti, and F. S. Mukti, "Optimalisasi Nilai Throughput Jaringan Laboratorium Menggunakan Metode Hierarchical Token Bucket (Studi Kasus: Stmik Asia Malang),"Network Engineering Research Operation, vol. 5, no. 2, pp. 83-90, 2020.

[2] B. D. Saputra, "Sistem Informasi E-Business Pada Studio Foto Alluvio Photography," Network Engineering Research Operation, vol. 5, no. 2, pp. 66-73, 2020.

[3] D. Sasongko and S. Nugroho, "The Performance Comparison of Software as a Service for the First Step Cloud Computing Adoption Processes," International Journal of Scientific Research in Computer Science, Engineering and Information Technology (IJSRCSEIT), vol. 5, no. 5, pp. 85-91, Sep. 2019, doi: https://doi.org/10.32628/CSEIT195457. 
[4] A. Suprapto, "Analisis dimensi kebutuhan pra implementasi e-learning untuk meningkatkan mutu layanan pendidikan kampus di era revolusi industri 4.0," Attarbiyah, vol. 28, pp. 81-97, 2018.

[5] H. Wijaya, "Review dan Analisa Faktor-Faktor Yang Mempengaruhi Kecepatan Akses Halaman Website," Ultimatics: Jurnal Teknik Informatika, vol. 11, no. 1, pp. 38-45, 2019.

[6] M. R. Maulana, E. B. Susanto, and S. W. Binabar, "ANALISA PERFORMA WEBSITE PEMERINTAH KABUPATEN BATANG," IC-Tech, vol. 15, no. 1, 2020.

[7] A. Muchali and J. Budiarto, "Analisis Pengujian Performa Website Jabatan fungsional Perguruan Tinggi," Seminar Nasional TIK dan Ilmu Sosial (SocioTech) 2017, vol. 1, no. 1, pp. 157-161, Oktober 2017.

[8] "What to Consider When Building or Buying a Load Testing Solution." https://k6.io/what-to-consider-when-building-or-buying-a-load-testing-solution\#making-yourload-testing-solution-reliable (accessed Jan. 30, 2021).

[9] "Load testing for engineering teams | k6." https://k6.io/ (accessed Jan. 30, 2021).

[10] R. Maulana, F. Wiharjo, and others, "Software Testing Pengujian Performansi dan Tingkat Stress Pada Website Ekspedisi JNE dan TIKI," Jurnal INSYPRO (Information System and Processing), vol. 2, no. 1, 2017.

[11] I. M. E. Listartha, "Pengujian Performa dan Tingkat Stress pada Website Legalisir Ijasah Online Universitas Pendidikan Ganesha," Electro Luceat, vol. 6, no. 1, pp. 66-73, 2020.

[12] M. Christina, "Pengujian Performa dan Tingkat Stress pada Website Bapenda Jawa Barat, Jawa Tengah, dan Jawa Timur," Media Informatika, vol. 18, no. 2, pp. 101-106, 2019.

[13] S. Fitri, "Pengujian kinerja website dan analisis dekriptif kualitas website pada situs Universitas (Studi kasus pada Universitas Muhammayah Tasikmalaya)," Jurnal Maklumatika, vol. 3, no. 2, pp. 169-181, 2017.

[14] B. Stringam and J. Gerdes, "Service gap in hotel website load performance," International Hospitality Review, 2019.

[15] G. Guntoro, D. S. Kusumo, and A. Adiwijaya, "Analisis Web Performance dan Load Test Studi Kasus: Topologi Cloud Microsoft Azure Test Rig pada I-banking Bank XYZ," eProceedings of Engineering, vol. 2, no. 1, 2015.

[16] "Introduction." https://k6.io/docs/test-types/introduction (accessed Jan. 31, 2021).

[17] "Ramping VUs." https://k6.io/docs/using-k6/scenarios/executors/ramping-vus (accessed Mar. 06, 2021).

[18] D. Scheneider, "Bounce Rate: What You Need to Know and How to Improve." https://www.similarweb.com/corp/blog/bounce-rate/ (accessed Jan. 22, 2021). 